\title{
"Spessart" field project of Weihenstephan-Triesdorf University of Applied Sciences reaches final stage of the 2020 EU-Natura 2000 Award
}

\author{
Bernd Stöcklein, Christoph Moning \& Volker Zahner
}

Keywords: Field study project Natura 2000, European Natura 2000 Award, communal forests, working norms LWF, Natura 2000 sites, special support programme Bavaria, nature conservation contract programme in forests (VNP Wald)

\section{Abstract}

For the first time, a field project run by Weihenstephan-Triesdorf University of Applied Sciences has reached the finals of the 2020 European Natura 2000 award. Just as special as the project's presence among the finalists in the Communication category has been the initial concept of the Spessart project. This field study was designed in close cooperation with specialist and municipal authorities, and local inhabitants, and was conducted in sites of communal and city forests in the Main-Spessart district. Over a period of 17 years, student groups focused on three overarching survey parameters, which were in accordance with the working instructions of the Bavarian State Institute of Forestry: Presence of Natura 2000 habitats, habitat structures, and Fauna (with a particular focus on value-adding bird species and bats). The evaluations of each parameter were carried out separately and then combined into an overall evaluation. Following the data analysis and evaluation phase, recommendations for optimizations and subsidies were made. The final results were presented to interested local people, authorities and the press. This information could inform and support grant and subsidy applications for nature and forest conservation efforts.

\section{Profile}

Protected area

Natura 2000 habitats

Mountain range

Low Mountain Range

Spessart

Country

\section{Germany}

\section{Introduction}

For the first time, a field project of WeihenstephanTriesdorf University of Applied Sciences (HSWT) has reached the finals of the 2020 European Natura 2000 award, which is designed to reward excellence in the management of Natura 2000 sites. It recognizes best practice in their management and conservation achievements, highlighting the benefits of the network for local economies, and increasing public awareness about Europe's valuable natural heritage (EC 2019).

Just as special as the Spessart project's reaching the finals in the Communication category of the award is the initial concept of the project itself. Natura 2000 Spessart seeks to connect research and people for the benefit of nature. It is conceived as an external field study project (i. e. outside Weihenstephan), and functions in close cooperation with specialist authorities, municipal authorities and local people. Over the last 17 years, week-long study projects run jointly by the Department of Forestry and the Department of Landscape Architecture at HSWT (Germany) have been conducted in selected sites of communal and city forests in the Main-Spessart district (Figure 1). The only exceptions were the selection of two sites in neighbouring areas: in 2011 in the city of Karbach, and in 2018 in the Steigerwald, part of the Gräfholz-Kehrenberg nature reserve near Bad Windsheim. Some trial sites are designated nature conservation areas, Naturwaldreservat (natural forest reserves), and / or Natura 2000 sites. The Spessart is Germany's largest mixed deciduous forest complex, situated in the low mountain region, along the Lower Main river, between Würzburg and Aschaffenburg (see Figure 1).

The sites investigated cover between 50 ha and 200 ha and are under communal ownership. The district managers of the local forests selected the sites in agreement with the municipalities. The HSWT students analysed the sites in accordance with the working norms of the Bavarian State Institute of Forestry (LFW) for Natura 2000 sites (Müller-Kroehling et al. 2004), focusing on three particular, overarching, survey parameters. These parameters remained the same for the duration (over 17 years) of the joint project.

1. Presence of Natura 2000 habitats (according to the relevant bioindicators for the identification of plant/vegetation)

The Natura 2000 habitat types present in the study areas were determined based on plant indicator species, including forest tree species (see Figure 2).

\section{Habitat structures, such as biotope trees and} coarse woody debris / deadwood

The number of biotope trees (trees with cavities, etc.) as well as the occurrence of standing and lying dead wood was determined separately for coniferous and deciduous trees. Measurements were in numbers / square metre and were made along transect lines. The length of the transect lines was in direct proportion to the area of the entire sampling site (see Figure 3). 


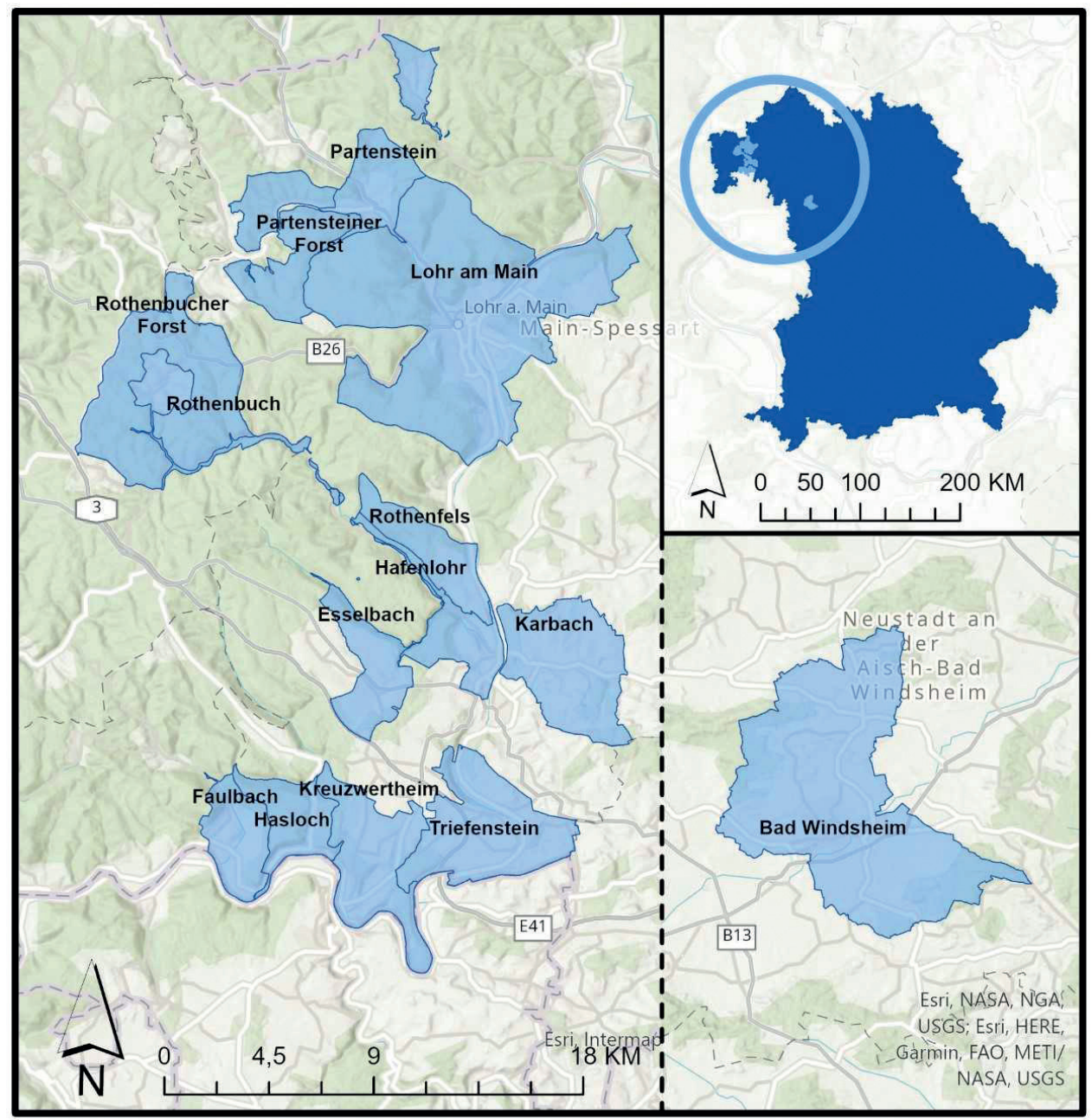

Figure 1 - Overview of the municipalities with trial sites in Spessart, Lower Franconia, within the district of Main-Spessart, and in Bad Windsheim, Middle Franconia, within the district of Neustadt / Aisch-Bad Windsheim, North Bavaria, over the project duration 2003-2019. The inset (top right) shows the location of the trial sites within Bavaria.

3. Fauna (with a particular focus on the populations of value-adding bird species and bats)

Using recordings of bird calls (especially for Collared Flycatcher, Middle Spotted Woodpecker and Black Woodpecker; see Figure 5), the students mapped

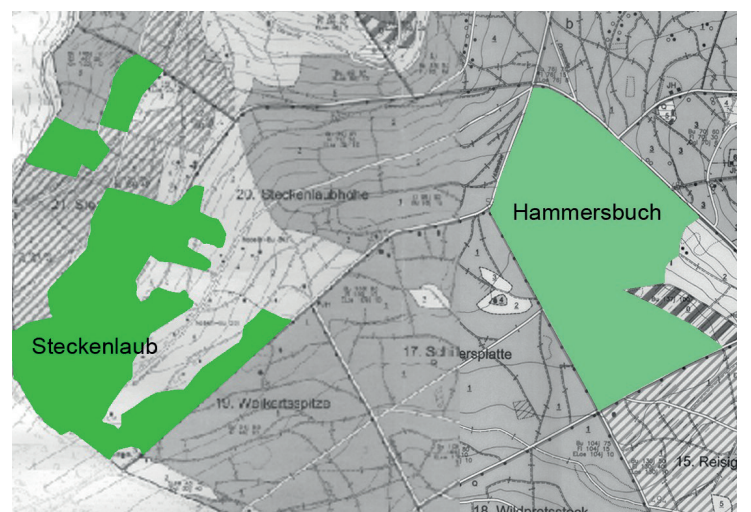

Figure 2 - Sites for the survey of floral biotopes in the municipal forest of Lohr. (C) Bayerische Vermessungsverwaltung - wmm.geodaten.bayern.de the occurrence and distribution of valuable bird species according to the Natura 2000 habitat types. Each Natura 2000 habitat type was investigated along an individual transect line (Figure 4). They also conducted random bat-detector studies to determine the range of bat species present.

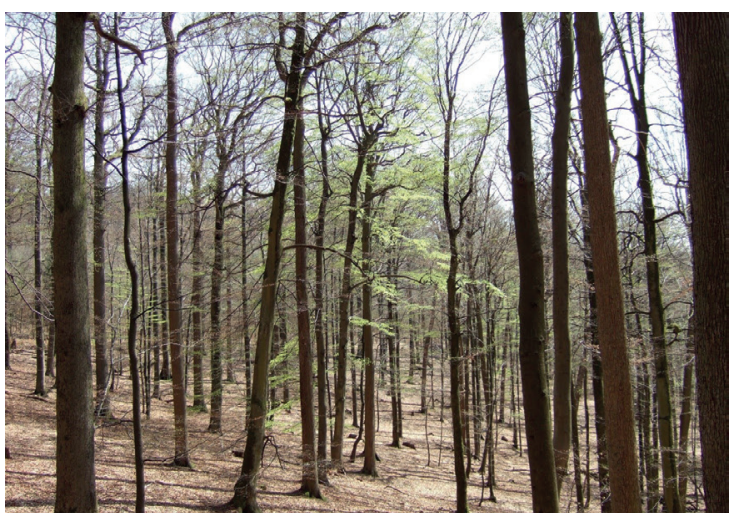

Figure 3-Woodrush-beech forest within the municipal forest of Rothenbuch. (C) Bernd Stöcklein 


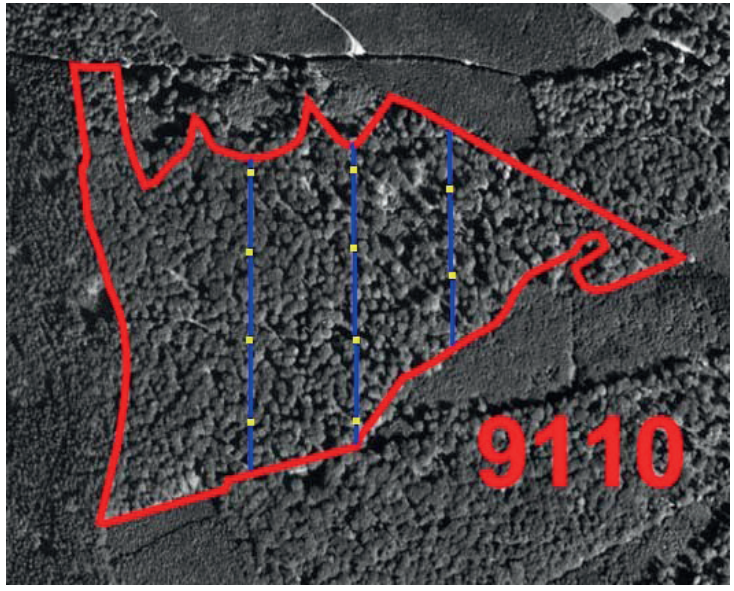

Figure 4 - Location of the transects for monitoring valuable bird species in the natural forest reserve Harfe (Rothenbuch). (C) Bayerische Vermessungsverwaltung - wmw.geodaten.bayern.de

The students documented the results of the surveys digitally, following the required approach and methods, and then evaluated the survey parameters separately. The state of preservation of the areas investigated was evaluated on a three-level scale $(A-C)$ : $\mathrm{A}=$ excellent condition; $\mathrm{B}=\operatorname{good}$ condition, and $\mathrm{C}=$ average to poor condition.

The students carried out evaluations of each parameter separately and then combined them into an overall evaluation. Following the data analysis and evaluation phase, they developed recommendations for optimizations and subsidies, as part of the contractual Bavarian nature conservation policy (nature conservation contract programme in forests VNP Wald, Bavarian State Ministry of the Environment and Consumer Protection 2019; see Table 1). The basic principle is that according to Natura 2000 any deterioration of the current condition must be avoided.

At this stage, it did not matter whether the trial sites were situated within the Higher Spessart Natura 2000 site or not. To inform the municipalities concerned, selected preliminary results along the three survey pa-
Table 1 - Contractual Bavarian nature conservation policy (special support programme VNP Wald). Bavarian State Ministry of the Environment and Consumer Protection 2019).

\begin{tabular}{|l|}
\hline $\begin{array}{l}\text { The special support programme for forest VNP Wald ena- } \\
\text { bles compensation payments }\end{array}$ \\
\hline Sample of relevant subsidy options \\
\hline Conservation of old and biotope trees (directive 2.1.1.2) \\
\hline $\begin{array}{l}\text { Maintenance of coarse woody debris/deadwood (directive } \\
2.1 .1 .3 \text { ) }\end{array}$ \\
\hline Waiver of use (in lieu of sustainable use) (directive 2.1.1.1) \\
\hline $\begin{array}{l}\text { Creation or maintenance of open spaces in forests (directive } \\
\text { 2.1.4.1) }\end{array}$ \\
\hline Eligibility criteria \\
\hline Share of biotope trees \\
\hline Share of coarse woody debris/deadwood \\
\hline Diameter breast height (DBH) \\
\hline
\end{tabular}

rameters were presented in the context of a go-and-see field trip to the sites. These results were prepared by the district foresters and the supervising professors during internship weeks, with professors and students demonstrating the methods applied (e.g. acoustic surveys to sample avian communities and territories) along a predefined walking tour. Furthermore, approaches to determine biotope types were also illustrated, e. g. by showcasing the types of plants surveyed and the individual habitat structures identified, such as coarse woody debris and value-adding structures of biotope trees (such as nesting holes and tree cavities). Leveraging such tangible examples had at least four major advantages. First of all, it made it possible to effectively inform all interested parties about Natura 2000 sites as important places of European natural heritage (i.e. what they sheltered by way of species and habitats, as well as specific landforms). Second, it made it possible to assess the effectiveness of the state's financial support for conservation. Third, it vividly illustrated the approaches used in the survey and evaluation phase. Finally, it enabled the discussion of the recommendations for the forest areas that had been drawn from the study. This format ensured that all suggestions, preferences and requests by the mu-
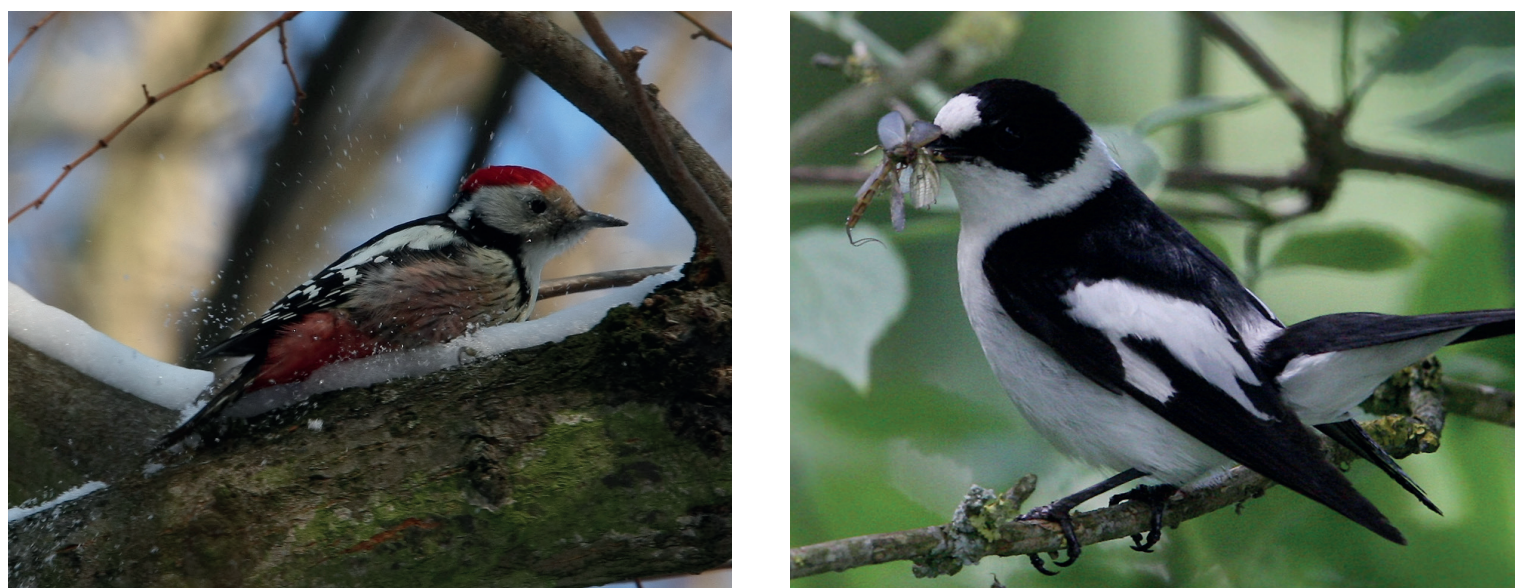

Figure 5 - Dendrocoptes medius (left); Ficedula albicollis (right). (C) Christoph Moning 
nicipalities and their inhabitants could be included in the final recommendations. These recommendations were used by the responsible authorities (e.g. LFW / local conservation authority) as up-to-date data for the municipality's application for funding for the nature conservation contract in forests (VNP Wald).

After completing the inventory surveys during the field project week, the students worked in groups, under the supervision of their professors, discussing the results in preparation for a final public presentation, which the students delivered to an audience of interested local citizens, authorities and the press. The final results provided the municipalities with detailed and up-to-date inventories and recommendations, including: restricting the collection of firewood by local people to locations outside the trial areas, which would increase significantly the amount within the trial areas for the populations of insects and other fauna; municipalities should therefore set aside other areas for the collection of wood; preservation of biotope trees; the re-routing of hiking trails to avoid species sensitive to disturbance (e.g. Black Stork). Local nature conservation authorities and the office for food, agriculture and forestry used the information to inform and support grant applications for nature and forest conservation efforts, as well as to provide decision support. The students particularly appreciated experiencing at first hand the importance of their work, as it acted as the basis for further implementations of concrete measures. Specifically, the Bavarian government granted subsidies of $€ 800000$ for the Spessart region, based on the evaluations conducted by the students. These subsidies were given to communities specifically to support nature conservation in their community forests. (Municipalities traditionally own large forest tracts in the Spessart region.) The students' work also supported local foresters in drawing up management plans for the communities. Finally, the VNP Wald generated funds that were used to subsidize municipal projects based on the Natura 2000 programme.

Initiated by HSW'T, the project reached the Finals of the 2020 EU-Natura 2000 awards, in the Communications category. (The winner in the Communications category was the French project, Eau la la!!! Eco-tips for sea and shore!.) The results demonstrated widespread public support for conservation initiatives generally, as finalists were voted for, EU-wide, by the public. In Spessart specifically, the awards attracted broad interest from all municipalities with forest areas, drawing attention to the objective new data. The results of the studies were seen not as a limitation for management, but as feeding into change for sustainable development, with subsidies from the Bavarian State Ministry of the Environment and Consumer Production being made available for the municipalities.

\section{References}

Bavarian State Ministry of the Environment and Consumer Protection 2019. Bayerisches Vertragsnaturschutzprogramm Wald (VNP Wald). Available at: https://www.stmuv.bayern.de/themen/naturschutz/ naturschutzfoerderung/vertragsnaturschutzprogramm_wald/index.htm (accessed 03.12.2020)

EC [European Community] 2019. European Natura 2000 Award. Available at: https://ec.europa.eu/ environment/nature/natura2000/awards/the-award/ index_en.htm (accessed 03.12.2020)

Müller-Kroehling, S., M. Fischer, H.-J. Gulder, H. Walentowski \& C. Kölling 2004. Arbeitsanweisung zur Fertigung von Managementplänen für Waldflächen in Natura 2000-Gebieten. Landesanstalt für Wald und Forstwirtschaft. Freising. Available at: https://www. lwf.bayern.de/mam/cms04/biodiversitaet/dateien/ arbeitsanweisung.pdf (accessed 03.12.2020)

VNP-Wald 2020. Bayerisches Vertragsnaturschutzprogramm Wald. Available at: https://www.stmuv. bayern.de/themen/naturschutz/naturschutzfoerderung/vertragsnaturschutzprogramm_wald/index.htm (accessed 03.12.2020)

\section{Authors}

\section{Bernd Stöcklein}

was Professor of Zoology and Animal Ecology at the Department of Landscape Architecture of Weihenstephan-Triesdorf University of Applied Sciences, a post from which he retired in 2016. E-mail: bernd. stoecklein@hswt.de

\section{Christoph Moning}

is Professor of Zoology and Animal Ecology at the Department of Landscape Architecture of Weihenstephan-Triesdorf University of Applied Sciences. E-mail: christoph.moning@hswt.de

\section{Volker Zahner}

is Professor of Zoology and Wildlife Ecology at the Department of Forest Ecology and Management of Weihenstephan-Triesdorf University of Applied Sciences. E-mail: volker.zahner@hswt.de 